\title{
GAMBARAN KUALITAS TIDUR DAN FUNGSI KOGNITIF PADA PASIEN PPOK DI BBKPM MAKASSAR
}

\section{Arif Budiman', Abdul Majid², Ilham Syam³, Suradi Efendi ${ }^{4}$}

Email : arifbudiman1121@gmail.com

1,3,4Sekolah Tinggi Ilmu Kesehatan (STIK) Makassar, Indonesia

2Universitas Hasanudin Makassar, Indonesia

\begin{abstract}
Poor sleep quality in patients with Chronic Obstructive Pulmonary Disease is caused by shortness of breath, coughing and excessive secretion production. Someone who has good sleep quality will affect his cognitive function, where sleep stage is associated with cerebral blood flow. Increased oxygen consumption can help store memory and learning related to cognitive function. Disorders of cognitive function will affect someone's productivity and even loss of independence. The incidence of COPD increases every year. By BBKPM 2015 that there were 130 patients, 142 in 2016 and 182 in 2017. This study aimed to describe the quality of sleep and cognitive function in COPD patients. This was descriptive study in that number of sample was 52 from 182 populations diagnosed with COPD at BBKPM Makassar. Data collection applied PSQI questionnaires to measure sleep quality and MMSE questionnaire to measure cognitive function.The results revealed that from 52 respondents, 35 (67.3\%) performed poor sleep quality while 17 (32.7\%) had good sleep quality with average score on PSQI 6.92. In addition, from 52 respondents, 29 (55.8\%) had impaired cognitive function while 23 (44.2\%) had normal cognitive function with average score on MMSE 22.77.It concluded that patients with COPD experienced poor sleep quality and cognitive impairment. It is encouraged to COPD patients to reduce strenuous activities in order to avoid shortness of breath.
\end{abstract}

\section{ABSTRAK}

Kualitas tidur yang buruk pada pasien dengan Penyakit Paru Obstruktif Kronik disebabkan karena sesak napas, batuk dan produksi sekret yang berlebihan. Seseorang yang memiliki kualitas tidur yang baik akan berpengaruh terhadap fungsi kognitifnya, dimana pada tahap tidur dihubungkan dengan aliran darah ke serebral, peningkatan konsumsi oksigen yang dapat membantu penyimpanan memori dan pembelajaran yang berhubungan dengan fungsi kognitifnya. Gangguan pada fungsi kognitif akan mempengaruhi produktivitas seseorang bahkan hilangnya kemandirian. Kejadian PPOK semakin meningkat setiap tahunnya. Di BBKPM Makassar tahun 2015 pasien PPOK berjumlah 130 pasien, tahun 2016 berjumlah 142 dan tahun 2017 berjumlah 182 pasien. Tujuan penelitian untuk mengetahui gambaran kualitas tidur dan fungsi kognitif pada pasien PPOK. Penelitian ini merupakan penelitian deskriptif dengan sampel 52 orang dari 182 populasi yang terdiagnosa PPOK Di BBKPM Makassar. Untuk pengukuran kualitas tidur menggunakan kuesioner Pittsburgh Sleep Quality Index dan untuk pengukuran fungsi kognitif menggunakan kuesioner Mini Mental State Examination. Hasil penelitian ini menunjukan dari 52 responden, sebanyak 35 orang $(67,3 \%)$ memiliki kualitas tidur yang buruk dan 17 orang $(32,7 \%)$ mempunyai kualitas tidur yang baik dengan skor rata - rata pada PSQI 6,92 . Dan dari 52 responden, 29 orang $(55,8 \%)$ mengalami gangguan fungsi kognitif dan 23 orang (44,2\%) memiliki fungsi kognitif yang normal dengan skor pada rata - rata pada MMSE 22,77.Kesimpulan penelitian ini dapat digambarkan pasien dengan PPOK memiliki kualitas tidur yang buruk dan mengalami gangguan fungsi kognitif. Disarankan kepada pasien untuk mengurangi aktivitas yang berat untuk menghindari terjadinya sesak nafas.

\section{ARTICLE INFO}

Keywords:

Sleep Quality; Cognitive Function; COPD

DOI:

10.24252/kesehatan.v14i1.14140

Kata kunci :

Kualitas Tidur; Fungsi Kognitif; PPOK

\section{Pendahuluan}

Penyakit paru obstruktif kronik merupakan salah satu dari kelompok penyakit tidak menular yang masih menjadi masalah kesehatan masyarakat di Indonesia. PPOK memiliki tingkat Morbilitas dan Mortalitas yang cukup tinggi, baik di negara berkembang maupun di negara maju (1).

Data Badan Kesehatan Dunia (WHO) mengatakan pada tahun 2012 lebih dari 3 juta orang meninggal karena PPOK. Sedangkan pada tahun 2017 PPOK telah menempati urutan ke 4 sebagai penyebab utama kematian di Dunia dan WHO memperkirakan pada tahun 2020 PPOK menjadi penyebab kematian peringkat ke 3 di dunia (2) 
menunjukkan Prevalensi kejadian PPOK di dunia rata - rata berkisar 3 - 11\%. Menurut data penelitian dari Regional Chronic Obstruksi Pumunary Disease Working Group yang dilakukan di 12 negara di Asia Pasifik rata - rata prevalensi PPOK sebesar 6,3\%, dengan yang terendah 3,5\% di Hongkong dan Singapura, dan tertinggi di Vietnam sebanyak $6,7 \%$. Indonesia menunjukkan prevalensi sebanyak 5,6\% atau 4,8 juta kasus untuk PPOK derajat sedang sampai berat (3).

Kualitas hidup penderita PPOK merupakan ukuran penting karena berhubungan dengan keadaan sesak yang akan menyulitkan penderita melakukan aktivitas kehidupan sehari - hari atau terganggu status fungsionalnya seperti merawat diri, mobilitas, makan, berpakaian, aktivitas rumah tangga dan istirahat tidurnya (4).

Penurunan kualitas hidup yang dapat menyebabkan gangguan fungsional salah satunya gangguan kualitas tidur, Kualitas tidur yang buruk pada klien dengan PPOK disebabkan karena sesak napas, batuk dan produksi sekret yang berlebihan. Tidur yang tidak adekuat dapat mengakibatkan gangguan fisik dan psikologi (5).

Kualitas tidur yang buruk akan berdampak pada fisiologis seseorang seperti penurunan aktivitas sehari - hari, rasa lelah, lemah, kondisi neuromuskular yang buruk, proses penyembuhan menjadi lambat, daya tahan tubuh menurun, dan ketidakstabilan tanda vital. Selain itu, dampak psikologis dari gangguan tidur meliputi stres, depresi, cemas, tidak konsentrasi, dan koping tidak efektif (6).

Akibat kualitas tidur yang buruk pada pasien PPOK bisa menyebabkan tidak konsentrasi, tidak konsentrasi pada seseorang bisa menyebabkan gangguan kognitif pada seseorang. Karena Salah satu fungsi tidur selain untuk memelihara fungsi jantung juga sebagai pemulihan fungsi kognitif. Seseorang yang mendapatkan kualitas tidur yang baik akan berpengaruh terhadap fungsi kognitifnya, dimana pada tahap tidur dihubungkan dengan aliran darah ke serebral, peningkatan konsumsi oksigen yang dapat membantu penyimpanan memori dan pembelajaran yang berhubungan dengan fungsi kognitifnya (7).

Gangguan pada fungsi kognitif akan mempengaruhi produktivitas seseorang bahkan hilangnya kemandirian, terlebih penderita PPOK, pasalnya kemandirian seseorang akan terhambat karena berdasarkan tanda dan gejala seperti napas pendek, batuk berlebih, kelelahan, dan depresi dapat berdampak besar pada orang normal terutama pada pasien PPOK yang membutuhkan waktu berjam - jam untuk menyelesaikan hal kecil (8).

Sangat penting mengkaji fungsi kognitif pasien dengan PPOK dalam rangka mengoptimalisasi perawatan yang berorientasi pada pasien sebagai upaya pencegahan komplikasi dari PPOK, sesuai dengan hipotesis penelitian (9) yang menjelaskan bahaya dari komplikasi PPOK yakni terjadinya hipoksia kronik yang mana hipoksia kronik pada PPOK meningkatkan kejadian neurodegenerasi penyakit Al - zheimer, yang diakibatkan oleh disfungsi mitokondria dan aktivasi program kematian sel (8).

Pada Penelitian yang di lakukan oleh (10) menemukan adanya hubungan antara tingkat keparahan penderita PPOK dengan gangguan fungsi kognitif. Penelitian ini dilakukan dengan cara pengukuran fungsi paru, dimana terlihat rendahnya kadar oksigen atau (PaO2). Kadar PaO2 hanya dapat di lihat melalui pengukuran analisa gas darah melalui cara pengambilan darah arteri perifer. Rendahnya kadar oksigen yang menyebabkan terjadinya hipoksemia kronis. Hipoksemia kronis menyebabkan terjadinya atrofi hippokampus yang berperan sebagai kunci utama terjadinya gangguan kognitif pada penderita PPOK (10). 
Penyakit paru obstruksi kronik termasuk penyakit kronik yang dapat berdampak psikologis, baik depresi maupun ansietas. Gangguan kesehatan mental seperti gejala depresi dan ansietas pada pasien PPOK, memberi banyak kontribusi terhadap berbagai varian kualitas hidup dan salah satu dampak lain dari PPOK yakni terjadinya hipoksia kronik (8).

Penelitian ini dilakukan di BBKPM pada pasien PPOK, pemilihan BBKPM sebagai tempat penelitian karena BBKPM merupakan salah satu balai paru terbesar di Indonesia timur dan merupakan pusat rujukan paru di Indonesia timur dan ketersediaan sampel yang cukup tinggi khususnya pasien dengan PPOK yang setiap tahunnya terus bertambah. Sesuai dengan survei data awal pada data rekam medis pasien penderita PPOK menujukkan, jumlah pasien PPOK selama tiga tahun terakhir mengalami peningkatan setiap tahunnya. Pada tahun 2015 pasien (PPOK) berjumlah 130 pasien, pada tahun 2016 pasien (PPOK) berjumlah 142 pasien dan Pada tahun 2017 pasien (PPOK) berjumlah 182 pasien (11).

Berdasarkan data tersebut, peneliti tertarik untuk meneliti Gambaran kualitas tidur dan fungsi kognitif pada penyakit paru obstruksi kronik (PPOK) Di Balai Besar Kesehatan Paru Masyarakat Makassar.

\section{Metode Penelitian}

Jenis penelitian ini adalah penelitian kuantitatif dengan menggunakan desain Penelitian Diskriptif yang bertujuan untuk menggambarkan kualitas tidur dan fungsi kognitif pada pasien Penyakit paru obstruksi kroniks (PPOK). Penelitian ini dilakukan di ruangan poli pulmonal Balai Besar Kesehatan Paru Masyarakat Makassar pada tanggal 08 Maret - 28 Maret 2018. Populasi dalam penelitian adalah semua pasien yang terdiagnosa penyakit Paru Obstruksi Kronik di Balai Besar Kesehatan Paru Masyarakat Makassar yang telah memenuhi kriteria inklusi. Kriteria inklusi dalam penelitian ini adalah Responden dengan penyakit PPOK, mampu melakukan komunikasi dengan baik, tidak dalam kondisi kritis dan bersedia menjadi responden. Pengambilan sampel dalam penelitian ini adalah menggunakan teknik Assidental sampling yaitu sebanyak 52 sampel. Penelitian ini dilakukan dengan pengambilan data primer menggunakan Kuesioner dan wawancara. Kuesioner yang digunakan dalam penelitian ini kuesioner Pittsburgh Sleep Quality Index (PSQI) untuk mengukur kualiats tidur dan Mini Mental State Examination (MMSE) untuk mengukur fungsi kognitif. Data yang terkumpul diolah dan dianalisis secara deskriptif kemudian disajikan dalam bentuk tabel dan narasi.

\section{Hasil Penelitian}

1. Karakteristik responden

Tabel 2. Karakteristik Responden

\begin{tabular}{ccc}
\hline Karakteristik responden & n & \% \\
\hline Umur & & \\
Dewasa akhir (36 - 45 tahun) & 7 & 13,5 \\
Lanjut usia awal (46 - 55 tahun) & 10 & 19,2 \\
Lanjut usia akhir (56 - 65 tahun) & 15 & 28,8 \\
Manula (> 65 Tahun) & 20 & 38,5 \\
\hline Jenis kelamin & & \\
Laki - laki & 41 & 78,8 \\
Perempuan & 11 & 21,2 \\
\hline
\end{tabular}




\begin{tabular}{ccc}
\hline Pendidikan & & \\
Tidak sekolah & 9 & 17,3 \\
SD & 24 & 46,2 \\
SMP & 4 & 7,7 \\
SMA & 8 & 15,4 \\
Perguruan Tinggi & 7 & 13,5 \\
\hline Pekerjaan & & \\
Tidak bekerja & 4 & 7,7 \\
Petani & 16 & 30,8 \\
Nelayan & 7 & 13,5 \\
IRT & 7 & 13,5 \\
Pensiunan & 2 & 3,8 \\
PNS & 5 & 9,6 \\
Buruh & 5 & 9,6 \\
Wiraswasta & 6 & 11,5 \\
\hline Lama sakit & & \\
Lama $\geq 2$ tahun & 40 & 76,9 \\
Baru < 2 tahun & 12 & 23,1 \\
\hline Jumlah & $\mathbf{5 2}$ & $\mathbf{1 0 0 , 0}$ \\
\hline
\end{tabular}

Sumber : Data primer 2018

Berdasarkan tabel 2, dapat dilihat karakteristik responden PPOK berdasarkan kelompok umur terbanyak yaitu kelompok umur Manula ( $>65$ tahun) sebanyak 20 orang $(38,2 \%)$. Dan kelompok umur paling sedikit yaitu pada kelompok umur dewasa akhir (36 - 45 tahun) sebanyak 7 orang $(13,5 \%)$. Berdasarkan jenis kelamin, responden laki - laki yaitu sebanyak 41 orang $(78,8 \%)$, sedangkan responden perempuan sebanyak 11 orang $(21,2 \%)$. Berdasarkan tingkat pendidikan responden terbanyak yaitu tingkat pendidikan SD sebanyak 24 orang $(46,2 \%)$ dan tingkat pendidikan paling sedikit yaitu SMP sebanyak 4 orang $(7,7 \%)$. Dan pada pekerjaan responden terbanyak pada pekerjaan petani sebanyak 16 orang $(30,8 \%)$ dan yang paling sediki yaitu pensiunan sebanyak 2 orang $9(3,8 \%)$. Dan pasien PPOK yang lama sakit $\geq 2$ tahun sebanyak 40 orang $(76,9 \%)$ dan yang baru menderita PPOK $<2$ tahun sebanyak 12 orang ( $23,1 \%)$.

2. Analisis univariat

Tabel 3. Karakteristik kualitas tidur dan fungsi kognitif

\begin{tabular}{ccc}
\hline Variabel penelitian & $\mathbf{n}$ & $\mathbf{\%}$ \\
\hline Kualitas tidur & & \\
Buruk & 35 & 67,3 \\
Baik & 17 & 32,7 \\
\hline Fungsi kognitif & & \\
Gangguan kognitif & 29 & 55,8 \\
Kognitif normal & 23 & 44,2 \\
\hline Jumlah & $\mathbf{5 2}$ & $\mathbf{1 0 0 , 0}$ \\
\hline
\end{tabular}

Sumber : Data primer 2018

Berdasarkan tabel 3 terlihat bahwa dari 52 responden, sebanyak 35 orang $(67,3 \%)$ mengalami kualitas tidur yang buruk dan 17 orang (32,7\%) mempunyai kualitas tidur 
yang baik. Dan pada fungsi kognifitif dari 52 responden, sebanyak 29 orang (55,8\%) mengalami gangguan kognitif dan 23 orang (44,2\%) mempunyai fungsi kognitif yang normal.

Tabel 4. Nilai rata - rata kualitas tidur dan fungsi kognitif

\begin{tabular}{cccccc}
\hline & n & Minimum & Maximum & Mean & Std. Deviation \\
\hline Skor PSQI & 52 & 2 & 16 & 6,92 & 3,295 \\
Skor MMSE & 52 & 14 & 30 & 22,77 & 4,714 \\
\hline Jumlah & $\mathbf{5 2}$ & & & & \\
\hline
\end{tabular}

Sumber : Data primer 2018

Berdasarkan tabel 4 di atas dapat di lihat skor rata - rata kualitas tidur pasien PPOK berdasarkan kuesioner PSQI yaitu 6,92 (0 -21) dimana skor $\geq 5$ kualitas tidur buruk dan pada fungsi kognitif skor rata - rata pasien PPOK berdasarkan kuesioner MMSE yaitu 22,77 dimana skor $<24$ mengalami gangguan fungsi kognitif.

\section{Pembahasan}

\section{Karakteristik responden}

Kelompok umur dalam penelitian ini terbagi 4 yaitu, dewasa akhir (36 - 45) tahun, lanjut usia wal (46 - 55 Tahun), lanjut usia akhir (56 - 65 aahun) dan manula (> 65 tahun). Hasil penelitian pada karakteristik responden berdasarkan kelompok umur terbanyak yaitu kelompok umur Manula ( $>65$ tahun) sebanyak 20 orang (38,2\%) dari 52 responden. Penelitian ini menguatkan teori (12), Semakin bertambahnya usia, maka semakin besar risiko menderita PPOK ini dikarenakan di usia lanjut kondisi tubuh mulai menurun. Dan (2) mengatakan penuaan dapat menyebabkan kejadian PPOK.

Hasil penelitian ini sesuai dengan penelitian yang di lakukan oleh (13) di Amerika serikat yang melihat prevalensi asma dan penyakit paru obstruktif kronik mendapatkan hasil prevalensi PPOK meningkat dengan seiring bertambahnya usia. Hal ini sesuai gambaran responden yang berkunjung di poli klinik di Balai Besar Kesehatan Paru Masyarakat Makassar yaitu mayoritas kelompok umur lansia.

Hasil penelitian menunjukkan PPOK lebih banyak terjadi pada jenis kelamin laki- laki dari pada jenis kelamin perempuan yaitu laki - laki sebanyak 41 orang (78,8\%) dari 52 responden. Penelitian ini menguatkan teori (12) laki - laki lebih berisiko terkena PPOK dari pada wanita, mungkin hal ini terkait dengan kebiasaan merokok pada pria. Namun ada kecenderungan peningkatan prevalensi PPOK pada wanita yang merokok.

Sedangkan dalam (2), kejadian PPOK mengalami peningkatan dalam prevalensi, morbiditas, dan mortalitas pada wanita. Selama beberapa beberapa tahun terakhir ini sebagian besar disebabkan oleh peningkatan historis dalam konsumsi tembakau di kalangan perempuan. Sehingga Word Healt Organization dalam GOLD 2017 mengatakan sekarang perempuan memiliki risiko yang tinggi dalam prevalensi kejadian PPOK diseluruh dunia. Dan gambaran penderita penyakit paru obstruksi kronik pada poli klinik penelitian mayoritas responden yang berkunjung adalah dominan berjenis kelamin laki- laki.

Tingkat pendidikan SD merupakan tingkat pendidikan yang paling domina terjadinya PPOK yaitu sebanyak 24 orang (46,2\%) dari 52 responden, hal ini sesuai gambaran responden yang berkunjung di poli klinik di Balai Besar Kesehatan Paru Masyarakat Makassar dominan berpendidikan Sekolah Dasar. 
Pekerjaan sangat beragam jenisnya, dalam penelitian ini terdapat 8 jenis pekerjaan yang dimiliki oleh responden yang menderita PPOK. Berdasarkan penenlitian pekerjaan yang paling dominan terjadinya PPOK adalah petani yaitu sebanyak 16 orang (30,8\%). Pada teori (12), pekerjaan yang paling bersisiko terkena PPOK adalah pekerjaan tambang emas atau batu bara, industri gelas dan keramik yang terpapar debu silika, atau pekerja yang terpapar debu katun dan debu gandum, toluene diisosianat, dan abses, yang mempunyai risiko lebih besar terkena PPOK para pekerja dibandingkan yang bekerja ditempat lain.

PPOK merupakan penyakit kronik yang di derita dalam waktu yang cukup lama, namun dalam penenlitian ini lama menderita PPOK terbagi dalam dua kategori yaitu yang lama menderita $\geq 2$ tahun dan yang baru menderita $<2$ tahun. Dalam (12) Salah satu gejala PPOK adalah batuk bersifat kronis dan kambuhan yang terjadi pada hampir setiap hari selama sedikitnya 3 bulan dalam setahun untuk 2 tahun berturut - turut, sehingga dapat di simpulkan kroniks dapat dihitung $<2$ tahun. Hasil penelitian menunjukkan dapat dilihat rata - rata pasien PPOK yang berkunjung di poli klinik pulmonal menderita PPOK $\geq 2$ tahun sebanyak 40 orang (76,9\%) dari 52 responden. Seperti penelitian yang dilakukan oleh (14) tentang rata - rata lama menderita pasien PPOK didapatkan dari 60 sampel, 32 diantaranya menderita PPOK $\geq 2$ tahun.

\section{Analisa univariat}

\section{a. Kualitas tidur}

Berdasarkan hasil penelitian didapatkan dari 52 responden, sebanyak 35 orang $(67,3 \%)$ mengalami kualitas tidur yang buruk dan 17 orang $(32,7 \%)$ mempunyai kualitas tidur yang baik dengan nilai rata - rata 6,92 (0 -21) dimana skor $\geq 5$ kualitas tidur buruk. Penelitian ini sesuai teori (15) mengatakan tidur dapat disebabkan oleh beberapa faktor, salah satunya adalah penyakit. Seseorang yang mengalami sakit memerlukan waktu tidur lebih banyak dari normal. Namun demikian, keadaan sakit menjadikan pasien kurang tidur atau tidak dapat tidur. Misalnya pada pasien dengan gangguan pernapasan seperti asma, bronkitis, penyakit kardiovaskular, dan penyakit persarafan.

Sejalan dengan penenlitian sebelumnya yang dilakukan oleh (5) dimana penelitian ini melihat hubungan keluhan pernapasan dan faktor psikologis dengan kualitas tidur pasien penyakit paru dan di dapatkan penilaian rata - rata kualitas tidur pasien penyakit paru yang menjadi responden $66,1 \%$ memiliki kualitas tidur yang buruk, dan sebanyak 33,9\% responden yang memiliki kualitas tidur yang baik. Penilaian dalam penelitian tersebut menggunakan instrumen PSQI didapatkan hasil rata - rata sekitar 6,70 (0 - 21) dimana skor diatas dapat menggambarkan bahwa responden memiliki kualitas tidur yang buruk.

Berdasarkan hasil penelitian diperoleh gambaran bahwa gangguan tidur yang banyak dialami oleh pasien penyakit PPOK dalam penelitian ini adalah karena terbangun pada malam hari, keringat pada malam hari, menggigil, batuk dan tidak dapat bernapas dengan nyaman. Hasil tersebut sesuai dengan Penelitian kualitas tidur pasien yang dilakukan oleh (16) di Canada bahwa ketidaknyamanan akibat penyakit menjadi penyebab kualitas tidur yang buruk pada pasien dan penelitian ini menunjukkan bahwa lebih dari 60\% dari pasien dengan gejala batuk di malam hari. Sifat keluhan ini cukup bervariasi dan dapat spesifik tetapi mencakup gejala seperti insomnia, kelelahan siang hari, dan batuk (16) Kualitas tidur yang baik bukan masalah lama durasi tidur yang dilakakukan, tetapi tidur yang dijalani seorang individu menghasilkan kesegaran dan 
kebugaran ketika terbangun. Kualitas tidur mencakup aspek kuantitatif seperti durasi tidur, latensi tidur, serta aspek subjektif seperti tidur dan istirahat (17).

\section{b. Fungsi kognitif}

Berdasarkan hasil penelitian menggunakan kuisioner kognitif MMSE, tes fungsi kognitif yang dilakukan pada pasien PPOK dengan total responden 52 orang, sebanyak 29 orang $(55,8 \%)$ mengalami gangguan kognitif. Dengan nilai rata - rata 22,77 dimana skor < 24 mengalami gangguan fungsi kognitif.

Hasil penelitian sesuai dengan Penelitian yang di lakukan oleh (10) menemukan adanya hubungan antara tingkat keparahan penderita PPOK dengan gangguan fungsi kognitif. Penelitian ini dilakukan dengan cara pengukuran fungsi paru, dimana terlihat rendahnya kadar oksigen atau ( $\mathrm{PaO} 2)$. Kadar $\mathrm{PaO} 2$ hanya dapat di lihat melalui pengukuran analisa gas darah melalui cara pengambilan darah arteri perifer. Rendahnya kadar oksigen yang menyebabkan terjadinya hipoksemia kronis. Hipoksemia kronis menyebabkan terjadinya atrofi hippokampus yang berperan sebagai kunci utama terjadinya gangguan kognitif pada penderita PPOK (10)

Dan pada review yang dilakukan oleg (18) tentang gangguan kognitif pada PPOK, dimana review dilakukan selama 10 tahun terakhir pada 478 artikel yang mengatakan ada hubungan gangguan kognitif dengan PPOK. Dan pada review terbaru yang dilakukan oleh (18) pada 15 artikel mengatakan ada hubungan domain dalam kognitif dengan PPOK.

Faktor risiko independen yang paling jelas untuk penurunan kognitif pada pasien dengan PPOK berkurang ketersediaan oksigen sebagai hasil dari disfungsi paru - paru. Jika suplai oksigen tidak mencukupi untuk memenuhi kebutuhan metabolisme otak akibat gangguan mekanik paru - paru atau fungsi pernafasan tidak memadai pada pasien COPD. Oleh karena itu, hipoksia arteri tampaknya menjadi kontributor utama penurunan kognitif dengan tingkat yang lebih tinggi dari penurunan oksigen meningkatkan risiko disfungsi kognitif (19).

Penelitian yang dilakuakn oleh (19) sesuai dengan hipotesis penelitian (9) yang menjelaskan bahaya dari komplikasi PPOK yakni terjadinya hipoksia kronik yang mana hipoksia kronik pada PPOK meningkatkan kejadian neurodegenerasi penyakit Alzheimer, yang diakibatkan oleh disfungsi mitokondria dan aktivasi program kematian sel sehingga dapat menyebabkan fungsi kognitif terganggu. Berdarakan hasil penelitian dan teori diatas dapat di gambarkan bahwa terjadi gangguan kognitif pada pasien dengan PPOK. Berdasarkan dari hasil penelitian dan teori dapat digambarkan bahwa terjadi gangguan kognitif pada pasien dengan PPOK.

\section{Kesimpulan}

Berdasarkan hasil penelitian dapat simpulkan beberapa point, Yaiutu :

1. PPOK dominan terjadi pada usia $>65$ tahun sebanyak 20 orang $(38,5 \%)$ dan lebih banyak pada jenis kelamin laki - laki 41 orang (78,8\%) dari pada perempuan dan tingkat pendidikan SD lebih banyak menderita PPOK. PPOK terdapat pada berbagai jenis pekerjaan namun lebih banyak terjadi pada pekerjaan petani. Dan rata - rata pasien PPOk menderita PPOK $\geq 2$ tahun.

2. Hasil penelitian menggambarkan bahwa pasien PPOK mengalami kualitas tidur yang buruk sebanyak 35 orang $(67,3 \%)$ dari 52 responden dengan nilai rata - rata 6,92 dimana skor $\geq 5$ kualitas tidur buruk. 
3. Hasil penelitian menggambarkan bahwa pasien PPOK mengalami perubahan fungsi kognitif sebanyak sebanyak $29(55,8 \%)$ dari 52 responden dengan nilai rata - rata 22,77 dimana skor < 24 mengalami gangguan fungsi kognitif.

\section{Saran}

Untuk pasien Penyakit Paru Obstruktif Kronik sebaiknya jangan melakukan aktivitas yang berat yang dapat menyebabkan munculnya gejala yang mengganggu kebutuhan dasar seperti kebutuhan tidur dan fungsi kognitif dan untuk tenaga kesehatan sebaiknya meningkatkan sosilisasi tentang kesehatan khususnya PPOK

\section{Daftar Pustaka}

1. Muthmainnah, Restuastuti T, Munir SM. Gambaran Kualitas Hidup Pasien Ppok Stabil Di Poli Paru Rsud Arifin Achmad Provinsi Riau Dengan Menggunakan Kuesioner Sgrq. 2015;JOM FK Vol.

2. Global Initiative for Chronic Obstructive Lung (GOLD). Global Initiative for Chronic Obstructive Lung 2017. 2017;

3. Eni M. Instrumen Deteksi Dini Paparan Kronis Pestisida Dalam Pengendalian Faktor Risiko Ppok (Penyakit Paru Obstruktif Kronis) Pada Petani Di Kecamatan Gubug, Tanggungharjo Dan Tegowanu Kabupaten Grobogan. 2014;(Nidn 0627117501).

4. Siti K. Latihan Endurance Meningkatkan Kualitas Hidup Lebih Baik Dari Pada Latihan Pernafasan Pada Pasien Ppok Di Bp4 Yogyakarta Abstrak. 2013;1(1):20-32.

5. Ulfa hasanah, Permatasari A, Evi Karota. Hubungan keluhan pernapasan dan faktor psikologis dengan kualitas tidur pasien penyakit paru. 2016;6(1):45-50.

6. Indrawati N. Perbandingan Kualitas..., Nova Indrawati, FIK UI, 2012. 2012;

7. Hanifa Azmi. Hubungan kualitas tidur dan fungsi kognitif pada lanjut usia di panti sosial margaguna jakarta selatan. 2016;

8. Syahir Noer M. Gambaran fungsi kognitif pada penderita penyakit paru obsruktif kronis di RSU Kabupaten Tangerang Tahun 2015. 2016;

9. Carolis A De, Giubilei F, Caselli G, Casolla B, Cavallari M, Vanacore N, et al. Disease Is Associated with Altered Neuropsychological Performance in. 2011;402-8.

10. Li J, Huang Y. The Evaluation of Cognitive Impairment and Relevant Factors in Patients with. 2013;230022:98-105.

11. BBKPM. Rekam medis pasien Penyakit paru obstruski kronik (PPOK) 2017. In Makassar: Masyarakat, Balai Besar Kesehatan Parau; 2017.

12. Zullies I. Penatalaksanaan Terapinya. Penyakit Sistem Pernafasan. Yogyakarta.: Bursa Ilmu; 2016.

13. Kumbhare S, Pleasants R, Ohar JA, Strange C. Characteristics and Prevalence of Asthma / Chronic Obstructive Pulmonary Disease Overlap in the United States. 2016;13(2):803-10.

14. Ritianingsih N, Farial Nurhayati. Lama Sakit Berhubungan Dengan Kualitas Hidup Pasien Penyakit Paru Obstruksi Kronis ( PPOK ). 2017;17.

15. Tarwoto, Wartonah. Kebutuhan Dasar Manusiadan Proses Keperawatan. Edisi 5. Jakarta selatan: Salembah Medika; 2015.

16. Jen R, Li Y, Owens RL, Malhotra A. Sleep in Chronic Obstructive Pulmonary Disease : Evidence Gaps and Challenges. 2016;2016.

17. Tebo MC. Hubungan kualitas tidur dengan kejadian hipertensi di desa yordan kelurahan airmadidi bawah. 2016;

18. Torres-sánchez I, Rodríguez-alzueta E, Cabrera-martos I, López-torres I, Morenoramírez MP, Valenza MC. Cognitive impairment in COPD: a systematic review. 2015;41(061):182-90. 
19. Andrianopoulos V, Gloeckl R, Vogiatzis I. Cognitive impairment in COPD : should cognitive evaluation be part of respiratory assessment ? 2017;13(1):1-9. 